\title{
Ascending Aortic Thrombus as a Source of Right Coronary Artery Embolism in Acute Myocardial Infarction
}

\author{
Balázs Oltean Péter, István Kovács \\ Clinic of Cardiology, University of Medicine and Pharmacy, Tîrgu Mureș, Romania
}

\section{CORRESPONDENCE}

Balázs Oltean Péter

Str. Gheorghe Marinescu nr. 38

540139 Tîrgu Mureș, Romania

Tel +40 265215551

E-mail: olteanbalazs1@gmail.com

\section{ARTICLE HISTORY}

Received: 19 August, 2016

Accepted: 13 September, 2016
István Kovács • Str. Gheorghe Marinescu nr. 38 540139 Tîrgu Mureș, Romania. Tel +40 265215551 . E-mail:kov_istvan@yahoo.com
An ascending aortic thrombus is a rare condition, usually identified during a diagnostic evaluation and suggested by embolic complications. We present a case of floating thrombus in the right sinus of Valsalva, which caused acute myocardial infarction via embolisation in the right coronary artery.

A 62-year-old woman was admitted for acute ST-segment elevation myocardial infarction. From her medical history we mention non-ST-segment elevation myocardial infarction 6 months before the current admission, and a recent transient ischemic attack, suggesting recent thromboembolic events. The patient presented to our center with chest pain evolving for six hours and cardiogenic shock. The electrocardiogram showed 2-3 mm ST-segment elevation in leads DII, DIII, aVF and ST-segment depression in leads DI, aVL, V2V6. The troponin I $(0.327 \mathrm{ng} / \mathrm{ml})$ showed myocardial damage. The patient's condition was unstable, with a blood pressure of $84 / 51 \mathrm{mmHg}$ and a heart rate of $109 / \mathrm{min}$.

The emergency angiogram demonstrated a floating mass in the right coronary sinus, which extended into the right coronary artery, causing this complete occlusion (Panel A). The left coronary arteries were otherwise angiografically normal. After administration of intravenous anticoagulants and antiplatelets, we performed repetitive aspiration of the thrombus via thrombectomy catheter and catheter aspiration. Right coronary embolisation was shown on control angiography and ower-the-wire thrombectomy was performed. A huge mass of thrombus was extracted (Panel D), followed by Percutaneus Transluminal Coronary Angioplasty with a $3 \times 15 \mathrm{~mm}$ balloon and intracoronary administration of a IIb/IIIa inhibitor, followed by intravenous perfusion for 24 hours. Control angiography did not reveal any atherosclerotic lesion in coronary arteries (Panel C).

The prevalence of coronary artery embolism is unknown, but it is believed to be relatively uncommon. ${ }^{1,2}$ Percutaneus Transluminal Coronary Angioplasty has been successfully used to treat patient with AMI resulting from coronary artery embolism. In our case, catheter aspiration embolectomy has been successfully 

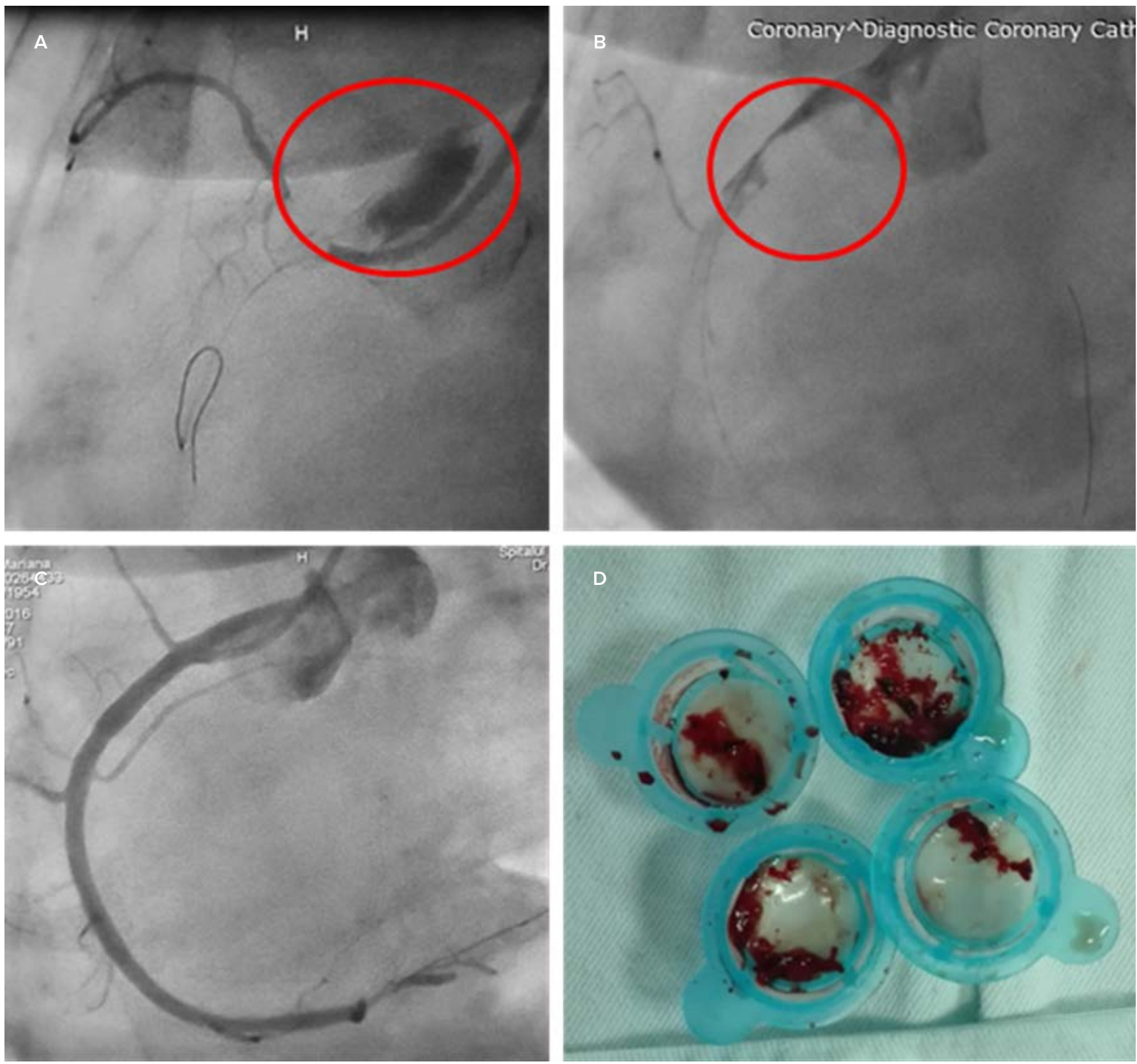

employed by several authors to aspirate thrombus from a native coronary artery. ${ }^{3,4}$ However, further investigations are required to elucidate possible clotting abnormalities in this case.

\section{REFERENCES}

1. Prizel KR, Hutchins GM, Bulkley $\mathrm{BH}$. Coronary artery embolism and myocardial infarction. Ann Intern Med. 1978;88(2):155-61.

2. Cheng TO. Coronary embolism. Int J Cardiol. 2009;136(1):1-3

3. Han DC, Kim JS, Lee SK, et al. Native aortic valve thrombosis: an unusual cause of acute ST-elevation myocardial infarction. Cardiovasc Pathol. 2013;22(3):e23-e26.

4. Shah NC, Munir SM, Alp NJ. Spontaneous Aortic Thrombosis Causing Left Main Coronary Occlusion in a Man With Secondary Polycythemia. JACC Cardiovasc Interv. 2011;4(8):934-935. 